\title{
CROWNED DENS SYNDROME (CDS) IN CALCIUM PYROPHOSPHATE DEPOSITION DISEASE (CPPD): RARE OR UNDERDIAGNOSED ENTITY?
}

Adriana Cristiane Machado ${ }^{1}$,, Renata Maria Monteiro Pinto ${ }^{1}$, Gustavo Fernandes Leobas ${ }^{1}$, Barbara Luzia Berredo Reis Alexandre ${ }^{1}$, Marina de Azevedo Martins ${ }^{1}$, Paula de Medeiros Nacácio e Silva ${ }^{1}$, Stan Richard Medeiros de Souza ${ }^{1}$, Renata Ferreira Rosa ${ }^{1}$, Rina Dalva Neubarth Giorgi ${ }^{1}$

1.Instituto de Assistência Médica ao Servidor Público Estadual, São Paulo (SP), Brazil.

*Corresponding author: drimachado89@hotmail.com

\section{BACKGROUND}

Calcium pyrophosphate deposition (CPPD) disease is an arthropathy caused by calcium pyrophosphate dihydrate (CPP) crystal deposits in articular tissues, most commonly fibrocartilage and hyaline cartilage. Calcium pyrophosphate deposition of the atlanto-occipital joint, also known as CDS, can cause periodic acute cervico-occipital pain with fever, neck stiffness and laboratory inflammatory evidences. The true incidence and prevalence of CDS in the general population or in those with CPPD remain unknown. We report two cases of CDS clinically characterized by asymptomatic CDS (case 1) and cervical spine myelopathy (case 2).

\section{CASE REPORT}

Case 1: B.S.S., 79-year-old female, presented knee pain and bilateral functional limitation associated with acute synovitis in the right knee. Laboratory results revealed hypomagnesemia and elevated inflammatory markers. Plain radiograph of the knees demonstrated CPPD-associated osteoarthritis. Chondrocalcinosis (CC) was also evidenced at other sites, such as wrists and symphysis pubis. Cervical spine CT showed atlantodental osteoarthrosis and the presence of calcifications near the anteroposterior tubercle of the atlas, compatible with asymptomatic CSD. Colchicine and magnesium replacement were started as a treatment option.

Case 2: J.F.A., 80-year-old male, had neck pain with stiffness, weakness on the right side of the body with hyperactive and symmetrical deep reflexes, except for the Achilles reflex, which were abolished, and urinary incontinence, which worsened progressively. No history of cervical trauma. Cervical spine CT demonstrated periodontal calcifications, C1-C2 subluxation, and cervical canal stenosis. Surprisingly, physical examination revealed knees joints inflammation and radiograph findings were consistent with CC. Patient was diagnosed with cervical myelopathy secondary to CDS and DPPC and clinically treated with colchicine and corticosteroid. Moreover, surgical removal of the posterior arch of $\mathrm{C} 1$ and enlargement of the foramen magnum with occipitocervical fixation was performed.

\section{CONCLUSION}

The CSD is defined as clinical presentation of episodic cervical pain and neck stiffness with associated radiological findings of calcifications surrounding the odontoid process. We described a symptomatic case with signs of cervical myelopathy, and an asymptomatic CDS, diagnosed during screening imaging studies for CC. Crowned dens syndrome is rarely considered as a diagnosis in part due to lack of awareness among clinicians. Recent studies suggest wide variation in the prevalence of CSD, ranging from 51 to $69 \%$. Cervical spine CT should be considered in elderly patients with neck pain, in particular when there is evidence of CPPD or $\mathrm{CC}$ in other joints. Moreover, other conditions such as polymyalgia rheumatica, giant cell arteritis or meningitis should be ruled out.

\section{KEYWORDS}

Crowned dens syndrome, Calcium pyrophosphate deposition disease, Neck stiffness, Crystal deposits. 